\title{
Chemically Modifying Viruses for Diverse Applications
}

\author{
Kritika Mohan ${ }^{\S}$ and Gregory A. Weiss ${ }^{*}$, , 市 \\ ${ }^{\S}$ Department of Chemistry and Department of Molecular Biology and Biochemistry, University of California, Irvine, California \\ 92697, United States
}

ABSTRACT: Long fascinating to biologists, viruses offer nanometer-scale benchtops for building molecular-scale devices and materials. Viruses tolerate a wide range of chemical modifications including reaction conditions, $\mathrm{pH}$ values, and temperatures. Recent examples of nongenetic manipulation of viral surfaces have extended viruses into applications ranging from biomedical imaging, drug delivery, tissue regeneration, and biosensors to materials for catalysis and energy generation. Chemical reactions on the phage surface include both covalent and noncovalent modifications, including some applied in conjunction with genetic

modifications. Here, we survey viruses chemically augmented with capabilities limited only by imagination.

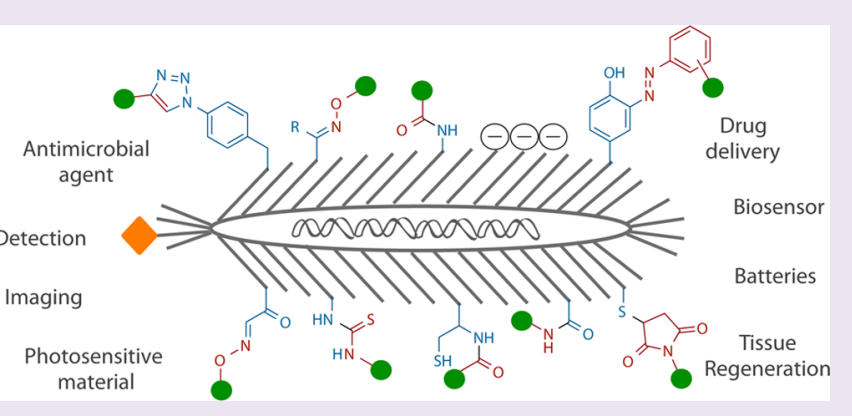

$\mathrm{B}$ eyond causing infectious diseases, viruses provide a useful nanometer-scale benchtop for chemical experiments and building complex biomedical reagents. Filamentous bacteriophages, such as the closely homologous M13 and fd phage, infect bacteria and propagate in a nonlytic manner. ${ }^{1-3}$ Furthermore, the lack of mammalian promoter sequences prevents them from causing human diseases. Such properties make M13 and fd phage nearly ubiquitous tools for a widerange of biotechnology applications.

These members of the Ff phage class have highly uniform structures. The phage $(\sim 1 \mu \mathrm{m}$ by $6 \mathrm{~nm})$ encapsulates an ssDNA genome in a flexible, long, rod-like protein coat formed entirely from multiple copies of five individual proteins. Along the entire length of the virion, $\sim 2700$ copies of the amphipathic, major coat protein, P8, are closely packed with a 5 -fold symmetry axis, and a free, unstructured $\mathrm{N}$-terminus; the proteins' C-termini interact with the phage genome through positively charged side chains. Each phage end is capped by five copies each of the paired minor coat proteins, P3/P6 and P7/ P9. ${ }^{1}$

Chemical biologists utilize phage to build nanoscale devices and materials for a wide variety of applications. Major attributes for the ease of phage-based applications include the low cost of scalable production, ease of manipulation, and wide temperature and $\mathrm{pH}$ stability. ${ }^{3,4}$ Furthermore, the relatively monodisperse phage self-assemble into rope-like bundles and liquid crystalline structures. The virus capsid presents a huge surface with easily modifiable residues to attach genetically nonencoded moieties for dense display. In this review, we focus on these versatile viruses, highlighting their tremendous potential as nanobenchtops.

\section{GENETIC MODIFICATION OF VIRUSES}

Phage display features a peptide or protein of interest fused to the outer terminus of the coat proteins. This approach provides a link between the genotype and the phenotype, with the encoding gene encapsulated by the coat protein and displayed fusion. ${ }^{1}$ The close-packed structure of the phage capsid prevents the display of most proteins with length $>6$ residues on every copy of the major coat protein..$^{5}$ To solve this problem, a phagemid system allows a mixture of unmodified and peptide-fused coat proteins. The phagemid display can result in phage particles having $\sim 10 \%$ peptide-fused P8s without affecting the packing of the phage capsid. ${ }^{6}$

The conventional usage of phage has been toward selections and biopanning. ${ }^{7,8}$ Peptide ligands have been reported for a variety of targets from protein biomarkers to small molecules such as TNT $^{9}$ and organic crystals, ${ }^{10}$ and the scope of selections has even been extended to screening for catalysts. ${ }^{11}$ Furthermore, a combination of different display methods can provide dual-displayed phage particles. This can be achieved either through combining modified genes or through modified phage propagation protocols utilizing double virus infection, ${ }^{12}$ as reviewed by Bratkovič and co-workers. ${ }^{13}$

\section{CHEMICAL MODIFICATION OF VIRUSES}

Though molecular display dominates conventional applications of viruses, nongenetic manipulation of the virus surface expands its repertoire of applications. Both covalent and noncovalent modifications, some in conjunction with genetic modifications, offer improvements on nature's functionalities. The modifications can be categorized into four broad classes, described below.

First, attachment to the functionalities inherent to amino acid side chains, Figure 1, is the most commonly used strategy, typically employing the reactive amino acid side chains present

Received: January 18, 2016

Accepted: March 1, 2016

Published: March 1, 2016 


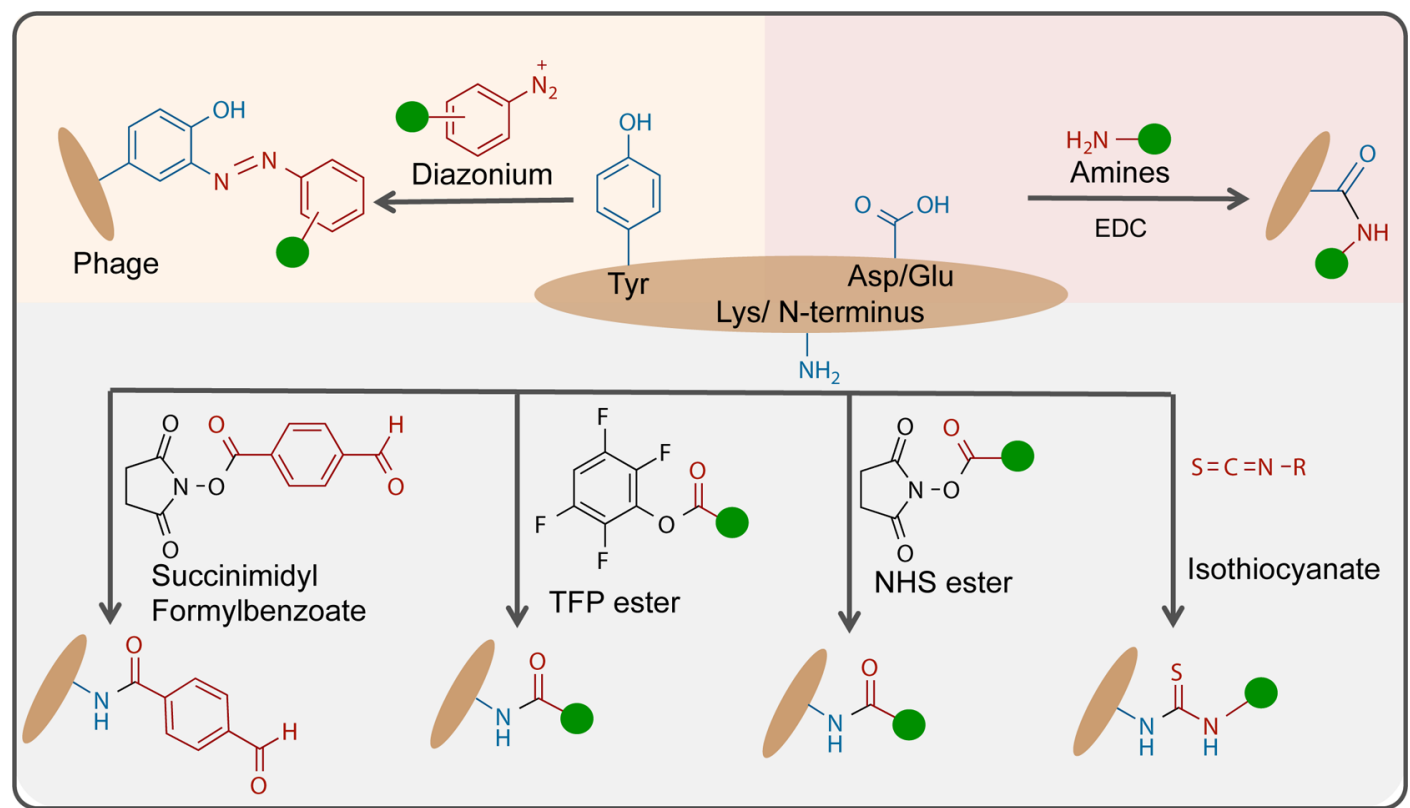

Figure 1. A compendium of the inherent functionalities present on the phage coat protein and the most commonly applied modification techniques. The green circle indicates the appended handle or the probe.

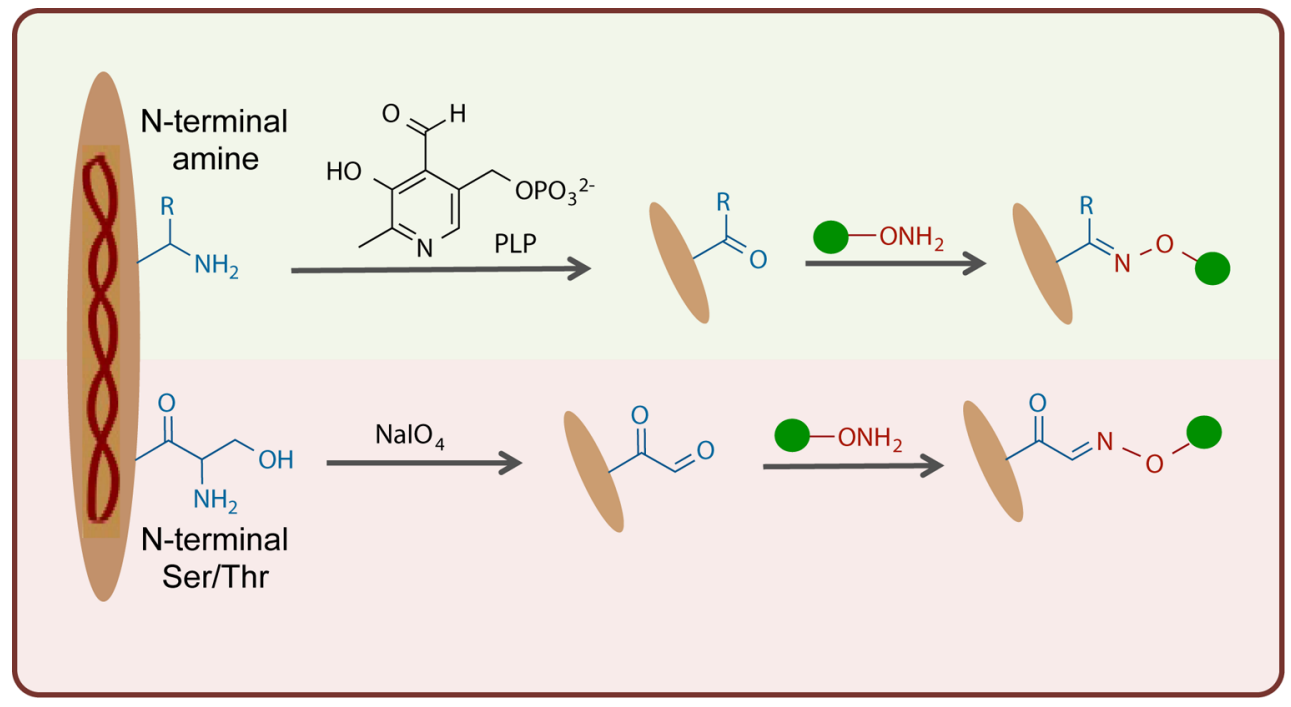

Figure 2. Chemically imparted functionalities providing an orthogonal aldehyde handle on the N-terminus of coat proteins.

on P8. Wang and co-workers compared the reactivities of the three prominent functionalities open to modification: carboxylates of Asp and Glu, phenol functionalities of Tyr, and the amines of Lys. The carboxylate groups can be activated through EDC treatment for coupling to amine-functionalized moieties, whereas the Tyr side chains can be coupled to diazonium salts. The amine groups, including the $\mathrm{N}$-termini, and Lys side chains could be coupled to NHS (N-hydroxysuccinimide) esters or other activated carboxylates (e.g., tetrafluorophenyl esters). ${ }^{14,15}$ Amine functionalities proved most reactive and efficient at such coupling reactions.

The next two classes of modifications include chemically and genetically imparted functionalities, which provide the desired handle for further modifications. In the second classification, modification of $\mathrm{N}$-terminal amines into aldehydes introduces a range of bioorthogonal reactions ${ }^{16}$ (Figure 2). The third class of chemical modifications begins with the genetic incorporation of either Cys or unnatural amino acids with desirable new functionalities (Figure 3). For example, genetically displayed $\mathrm{N}$ terminal Cys can be modified in a variety of ways including native chemical ligation. ${ }^{17}$ Naturally occurring selenocysteine, which offers high nucleophilicity, has also been genetically displayed using an opal stop codon suppressing tRNA and provides a reactive handle for further chemical modifications. ${ }^{18}$ Schultz and co-workers extended their approach to phage display, leading to the incorporation of $\mathrm{p}$-azidophenylalanine, which provides an easily modifiable azide handle on the phage surface. ${ }^{19,20}$

Though phage particles are stable to a wide variety of covalent bond forming conditions, the limited solvent accessibility of some residues can limit modification efficiency. To circumvent this limitation, noncovalent modifications to the phage coat have also been employed, forming the fourth set of classifications (Figure 4). Such modifications either utilize the 


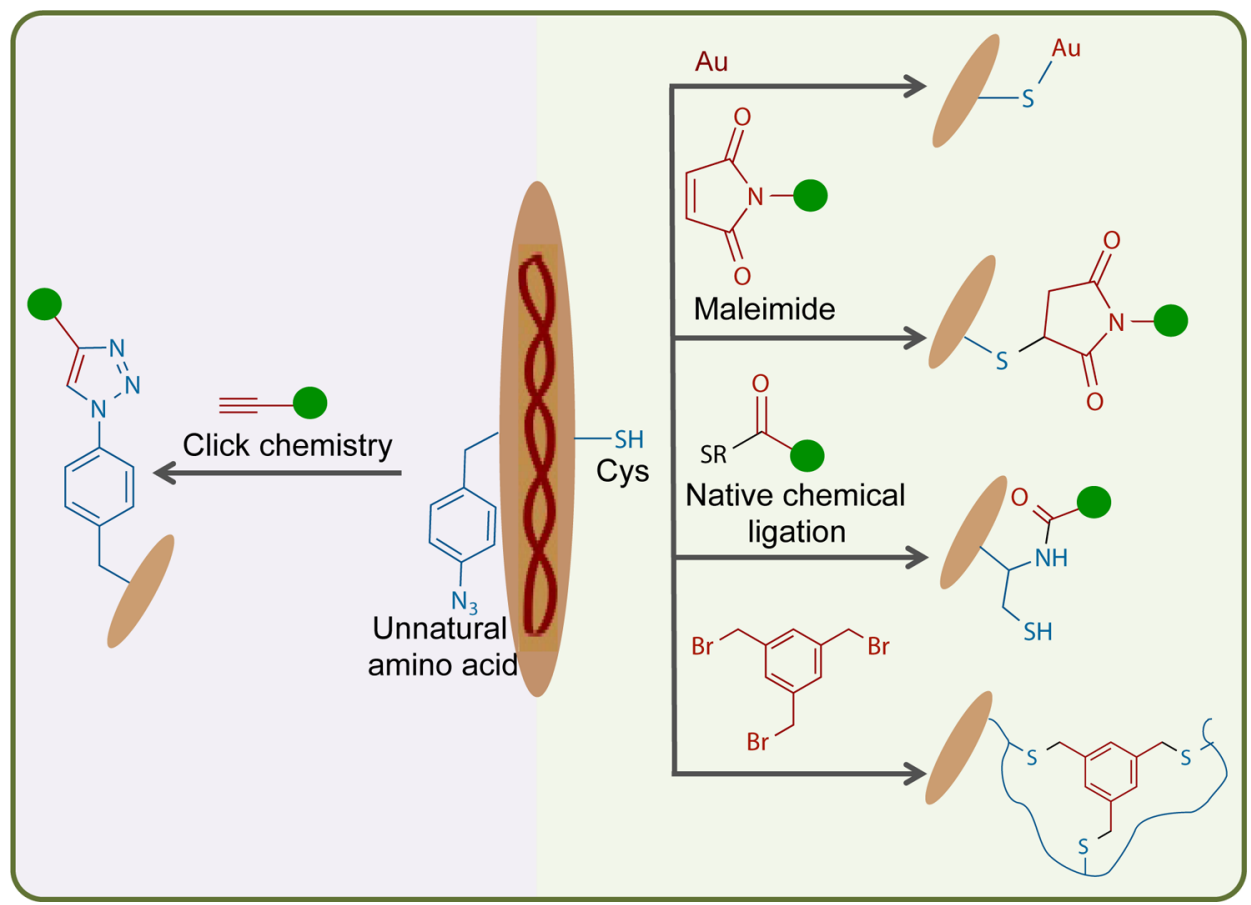

Figure 3. A compendium of functionalities genetically incorporated onto the phage surface, and the most commonly applied modification techniques.

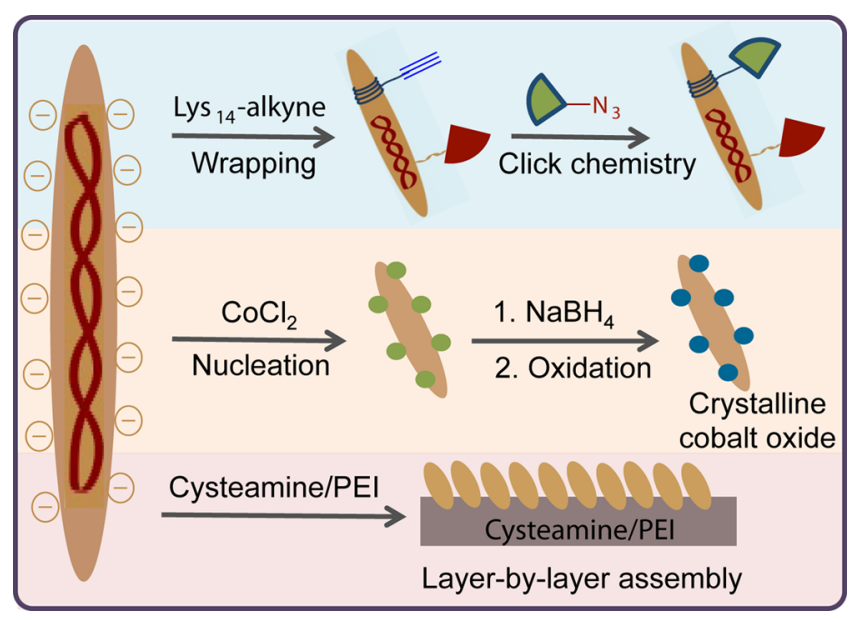

Figure 4. Noncovalent phage modifications utilize the negative surface charge on the phage.

high negative charge on the phage surface arising from the presence of Glu and Asp acid residues in the $N$-terminal region or build upon the amphipathic P8 coat protein. ${ }^{21}$ Here, we survey the chemical approaches to equip the viruses with such capabilities and functionalities.

\section{APPLICATIONS OF MODIFIED PHAGE}

Modified Phage for Enhanced Imaging. In recent years, improvements to in vivo imaging have started to address key issues to further extend this powerful technology. First, the chosen wavelengths of light must have minimal tissue autofluorescence and optical transparency. For example, absorbance at near-IR wavelengths (NIR) for cyanine dyes allows increased tissue penetration for imaging. Second, the imaging agents must be suitable for bioconjugation and soluble in water. Low solubility results in aggregation, which leads to intermolecular quenching of fluorescence emission. The high solubility of viruses and their versatility for surface modifications enables a myriad of imaging applications.

Conjugation of dyes to phage can take advantage of the large number of free amines on P8. Accordingly, alkyl-thioether cyanine dyes were NHS-activated for bioconjugation. Additionally, the modified phage displayed a peptide targeting the cell surface receptor VCAM-1 to allow binding and internalization into MCEC endothelial cells for imaging. ${ }^{22}$ Building on these results, an in vivo screening tool was also developed to rank phage-displayed peptides selected for binding to SPARC (Secreted Protein, Acidic and Rich in Cysteine). In this example, FITC-modified phage selectants were further examined for binding to SPARC in mice injected with Lewis lung carcinoma cells. In addition to ranking, the approach could identify unfavorable pharmacokinetics or nonspecific binding by SPARC ligand phage. The use of phage as a scaffold allowed attachment of up to 800 fluorophores/phage for higher sensitivity, without a loss in signal from proximity-based quenching. ${ }^{23}$

This straightforward approach to phage surface modification was applied to ratiometrically detect $\mathrm{pH}$ homeostasis and its disruptions, which are associated with cancer and other diseases. The ratios of $\mathrm{pH}$-sensitive to $\mathrm{pH}$-insensitive cyanine dyes allowed normalization and intracellular $\mathrm{pH}$ measurements. Again, the large, functional phage surface enabled 400-500 dyes conjugated per phage, thereby increasing the overall brightness and signal-to-noise ratios. The differences in the tissue penetration by light at the emitted wavelengths still posed a challenge for ratiometric determination. Nevertheless, the method allowed imaging and $\mathrm{pH}$ determination with $>95 \%$ accuracy. ${ }^{24}$ In a variation of this approach, a FRET pair was immobilized on the phage surface modified with NHS-activated cyclodextrin. $^{25}$ The FRET donor (fluorescein) and acceptor (rhodamine) were attached to adamantane for complexation within cyclodextrin. This approach gave a broader range of $\mathrm{pH}$ 
measurements $(5.0 \text { to } 8.4)^{26}$ than direct conjugation to amines on the phage surface ( $\mathrm{pH} 6.4-7.4){ }^{27}$

Further extension of IR imaging employed probes such as single-walled carbon nanotubes (SWNTs), which fluoresce in the second NIR window (950-1400 nm). This imaging moiety allows deep tissue penetration and low tissue autofluorescence. Despite their favorable properties, the hydrophobicity of SWNT poses a challenge for in vivo use. Belcher and coworkers solved this challenge by binding SWNTs through a P8displayed peptide on a highly soluble M13 phage. These phage also displayed the peptide sequence SPPTGIN on P3 for binding to SPARC (termed SPARC ligand phage). This allowed imaging at low probe concentrations of $2 \mu \mathrm{g} / \mathrm{mL}$ with tissue penetration of up to $2.5 \mathrm{~cm}$ in matrigel-based tissue samples. $^{28}$ The system could be used as probes for imageguided surgery of submillimeter tumors. ${ }^{29}$ In a related study, the bacterial enzyme sortase was used to chemoenzymatically attach fluorophores to P8 amines. By introducing orthogonal bioconjugation reactions, sortases increase the versatility of phage surface modifications. ${ }^{30}$

Phages also provide very effective scaffolds for MRI and PET scanning labels. For example, magnetic iron-oxide nanoparticles, bearing a positive charge, were assembled by electrostatic interactions on the surface of triglutamatedisplaying phage, resulting in 26 nanoparticles per SPARC ligand phage. This approach allows increased delivery to the target site and consequently improves image contrast. Phage again proved efficient as the scaffold bearing multiple nanoparticle copies, compared to conventional techniques, which would deliver single nanoparticles. ${ }^{31}$ Additionally, electrostatic interactions can drive phage to form biomimetic structures with noble metals such as $\mathrm{Au}$ and $\mathrm{Ag}$ for tumor imaging and photodynamic therapy. ${ }^{32}$

Due to the inherent specificity of phage for $F^{+}$bacteria, radiolabeled phage provide additional opportunities for selective imaging and distinguishing bacterial infections from inflammation. In this example, phage were functionalized with the activated NHS ester of mercaptoacetyltriglycine, which can then coordinate ${ }^{99 \mathrm{~m}} \mathrm{Tc} .{ }^{33}$ In a follow-up study, the approach was extended to four different types of phage allowing detection of host bacteria specific to each phage, though in vivo specificity remains a concern. ${ }^{34}$

Phage can also deliver hyper-polarized ${ }^{129} \mathrm{Xe}-\mathrm{MRI}$ contrast agents termed "Xe biosensors" for MRI and NMR. Xe has a natural affinity for hydrophobic cavities such as cryptophane A (CryA), but these molecular cages often need a solubilizing, targeting domain and multiple copies for improved sensitivity and specificity. The surface of phage provides the ideal benchtop for implanting such additional functionality. First, $\mathrm{N}$-terminal amines of P8 were transaminated in a novel reaction with pyridoxal phosphate (Figure 2). ${ }^{16}$ Additional solubility for the phage-CryA complex was provided by stepwise attachment with aminoxy-PEG followed by CryA (1:10 PEG/CryA). CryaA bound and unbound $\mathrm{Xe}$ offers distinct resonance frequencies. Polarized ${ }^{129} \mathrm{Xe}$ provides remarkably low detection limits $(230 \mathrm{fM})$ without much optimization. ${ }^{35}$ Next, cell targeting ability was provided by $\mathrm{P} 3$ proteins displaying a $\mathrm{scFv}$ binding to EGFR on MDA-MB-231 cells; the hyperpolarized Xe provided a 10000 -fold signal enhancement. ${ }^{36}$ The approach should have broad biocompatibility and essentially negligible background signal due to the unique inertness of Xe. Further developments in the synthesis of hyperpolarized $\mathrm{Xe}$ could transform phage-based analytics with routine access to sub-pM sensitivities.

Another approach to introduce the bio-orthogonal aldehyde functionality employed sodium periodate oxidation of $\mathrm{N}$ terminal Ser or Thr residues (Figure 2). ${ }^{37}$ The resultant glyoxal groups can then be selectively condensed with aminooxy-functionalized glycans. This bioconjugation can be more stable than hydrazones. ${ }^{38}$

Phage as a Drug Delivery Vehicle. Systemic delivery of disease therapeutics can lead to side effects in addition to the drug's desired activity. Toxic side effects can arise from the indiscriminate delivery of the drug to nontumor sites, where the compound can be modified, or bind inappropriately. Targeted drug delivery can ameliorate this problem by more precisely dosing the disease site, thereby decreasing the required drug dosage and its availability for off-target effects. Antibody-drug conjugates, the most successful targeted drug delivery approach, typically require expensive development and manufacturing. Phage offers a highly amenable platform for development, and also inexpensive production costs. However, a key consideration for drug delivery is elimination of toxic lipopolysaccharides during phage purification.

The tremendous hydrophilicity and solubility of phage particles has been demonstrated, for example, by the display of highly aggregation-prone membrane proteins. ${ }^{39}$ This approach has been applied to the conjugation of hydrophobic drugs (e.g., Doxorubicin, Dox) to reduce clearance of hydrophobic drugs by the mononuclear phagocyte system (MPS). Phage-displaying DFK, a cathepsin B cleavage site, were conjugated to Dox through EDC activation of the side chain carboxylate for drug loading levels of 3500 Dox/phage; the approach allowed reduced dosage and administration frequency. Furthermore, P3 of the modified phage displayed an IgG binding domain for binding to an antibody for cell targeting and internalization. A limitation of this cathepsin linkage is the release of the drug as an Asp adduct, which can render some drugs inactive. ${ }^{40}$ Building on this method, Belcher and co-workers reduced Dox loading to 257 Dox/phage and targeted the phage with a displayed SPARC ligand. The strategy yielded a 100 -fold more potent response, with a 20 -fold higher selectivity for SPARC-positive cells, and reduced nonspecificity resulting from hydrophobic adhesion through Dox to cell membranes. $^{41}$

Encapsulation of hydrophobic drugs has also been achieved through self-assembly of phage and block copolymers. Here again, phage provides solubilization and a large surface for target-specific modification. In one example, PCL-P2VP copolymer forms a core encapsulating Dox, and phage forms a shell for these spherical nanoassemblies of $\sim 200 \mathrm{~nm}$ diameter. The phage were premodified with folic acid through the EDC/ sulfo-NHS bioconjugation for folate receptor-mediated endocytosis by target cells. Protonation of the pyridine units in the polymer in the low $\mathrm{pH}$ endosome degrades the complex resulting in $\mathrm{pH}$-dependent release of Dox. The method, however, results in very large particles, which could render them susceptible to clearance by MPS. ${ }^{42}$

Multicomponent delivery vectors can apply phage for targeting a complex consisting of mesoporous Si particles and Au nanoparticles (NPs). The three components self-assemble due to their electrostatic interactions. ${ }^{43,44}$ The mesoporous Si was shaped to provide greater cell surface interactions before loading. The investigators planned a multistage delivery vehicle with the phage first recognizing the target through a displayed 
peptide before second stage delivery of carboxylated quantum dots, or amine-functionalized, superparamagnetic iron oxide NPs. ${ }^{44}$

Phage As an Extrinsic Antimicrobial Agent. The constant rise of multidrug resistant bacteria drives the need for improved antimicrobial therapies. Phage, especially lytic ones, can kill bacterial cells with high specificity and potency. But bacterial cell lysis can result in large quantities of released endotoxins potentially causing toxic shock. To avoid such effects, nonlytic phage, such as M13, could serve as a promising alternative. Furthermore, chemical modifications of the phage surface with currently existing drugs allow higher drug loading combined with targeted delivery. Thus, a high concentration of the antibiotic drug is delivered to the bacterial cell environment by phage, increasing the drug's potency.

In earlier studies, P8 amines were conjugated to an NHSactivated chloramphenicol-prodrug on phage-displaying an $S$. aureus targeting peptide on P3. The linker between chloramphenicol and the phage, glutaric acid, is cleavable by serum-based proteases, and the drug is active only after cleavage. ${ }^{45}$ In a further modification, the aminoglycoside neomycin was used as a solubility enhancing linker; the approach counters the hydrophobicity of chloramphenicol, which can disrupt phage stability at high concentrations. Drug loading can reach 10000 chloramphenicol molecules per phage. This phage-drug complex with neomycin linker was 20000 -fold more potent than the free drug, a 1000-fold improvement on the glutaric acid linker. ${ }^{46}$ In mice, the chloramphenicol-phage complex was found to be nontoxic with low clearance rates from blood and also generated a reduced immunogenic response compared to unconjugated drug. ${ }^{47}$ These results expand on the classic phage-based antibiotics, leveraging the high density workbench on the phage surface for drug delivery to cells.

Silverized materials offer another interesting antibacterial approach that minimizes the risk of developing resistance. To interact with the positively charged silver ions, phage were genetically modified to display a tri-Glu peptide to enhance the negative charge on their surface. Glutaraldehyde first crosslinked the phage to generate micrometer-scale-diameter phage fibers before coating with silver. These silverized phage demonstrate rapid bactericidal action within $300 \mu \mathrm{m}$ of the fiber. Such silverized phage coatings retained their antimicrobial activity even when coated on Kevlar fibers for use in future material development. ${ }^{48}$

Phage as a Biomimetic Matrix for Tissue Regeneration. Regeneration scaffolds for cultivating cell growth must mimic the environment of the extracellular matrix (ECM). Phage can provide both the ECM structure and requisite chemical cues. For example, liquid crystalline films comprised of self-assembled phage can serve as a scaffold providing a number of desirable properties, including long rod shape, nanometer-scale size, monodispersity, topographical features such as indentations and grooves, and the ability to attach ligands for cell-adhesion and growth. One early application applied aligned and self-assembled thin films of phage. Next, the phage amines were modified through reaction with an alkyne-functionalized NHS ester, which was further conjugated by the $\mathrm{Cu}^{\mathrm{I}}$-catalyzed azide-alkyne cycloaddition (click) reaction $^{49}$ to azide-functionalized RGD peptides. The RGD peptides are implicated in cellular recognition and attachment mediated through integrins. The click chemistry bioconjugation proceeds in aqueous media, at RTs, with typically high efficiencies, and can readily attach a variety of azide-derivatized moieties. The approach enables high density display with control over RGD peptide levels through the bioconjugation conditions. The resultant phage films enhance NIH3T3 cell adhesion and growth. ${ }^{50}$

Charge-based binding to the phage surface is a straightforward modification requiring little additional processing or reagents, Figure 4. Lee and co-workers deposited phage films on gold-coated glass slides to further characterize cell proliferation. As a lab-on-a-chip platform, the slides were first coated with positively charged cysteamine allowing charged layer stacking of negatively charged phage. Next, the growth of NIH3T3 cells was monitored using SPR spectroscopy. Cell proliferation directly correlated with growth factor concentration demonstrating the importance of dense bioconjugation on the phage surface. ${ }^{51}$ In a further extension of this approach, microfabrication techniques on gold substrates allowed patterning with phage on cysteamine films. ${ }^{52}$ Furthermore, the generation of three-dimensional phage matrices was achieved through electrostatic stabilization with cationic polymers. Poly-L-lysine and chitosan stabilized matrices showed $>90 \%$ cell survival. ${ }^{53}$

Bone regeneration therapy has also advanced through the application of modified phage. Both biochemical and topographical features of the artificially generated matrix affect cell proliferation and differentiation. Mao and co-workers generated a two-dimensional artificial ECM through layer-by-layer (LBL) self-assembly into parallel ridges of highly anionic phage and poly-L-lysine. A mixture of phage displaying RGD or PHSRN, which promotes RGD-based cell adhesion, was used to induce differentiation of mesenchymal stem cells ${ }^{54}$ and induced pluripotent stem cells (iPSCs). ${ }^{55}$ A phage-chitosan electrostatically stabilized matrix implanted into a 3D-printed bone scaffold allowed bone repair. The RGD-phage induced new bone formation through angiogenesis and osteogenesis. ${ }^{56}$

Modified Phage for Detection. Early and efficient detection and monitoring of disease-related markers, either proteins or whole cells, is key to favorable prognosis and patient outcomes. Ideally, point-of-care (POC) diagnostics should have quick turnaround times and very little sample preparation. The attributes cited above-high density, versatile functionalization-make phage useful scaffolds in a variety of detection schemes.

Lateral flow assays (LFA) are a rapid, easily commercializable form of POC diagnostics, provided key issues are addressed. For example, LFAs have high limits of detection (LODs), which hampers usage for virus detection. Dual-modified phage particles can increase the sensitivity of LFAs. For example, P3 coat proteins were genetically fused to the SamAvi peptide tag, which is biotinylated by the BirA enzyme. The biotinylated phage binds tetrameric neutravidin, which provides a linker to a biotinylated detection antibody. Additionally, P8 coat proteins were modified to enhance visualization of the LFA readout. First, Traut's reagent thiolated P8 amines. Next, the thiols were conjugated to maleimide-functionalized horseradish peroxidase (HRP) enzyme. This approach requires the addition of TMB as a substrate for HRP, thus detection is not reagent-free. Nevertheless, the study provided a detection limit of $10^{4} \mathrm{pfu} /$ $\mathrm{mL}$ for icosahedral MS2 viruses. ${ }^{57}$ Subsequently, a 100 -fold lower LOD than conventional $\mathrm{Au}$ NPs was obtained for detecting Norwalk virus like particles. ${ }^{58}$ In a subsequent study, the detection antibody was replaced with an aptamer linked to P3 through a biotinylated PEG linker and neutravidin. ${ }^{59}$ 
Fluorescence combined with diffraction-limited objects such as phage addresses the lack of quantitativeness associated with LFAs. For example, the Willson and Conrad research teams labeled phage with fluorescent dyes, allowing the use of automated image processing and direct counting for quantification. $^{60}$ As described above, P3 were functionalized with detection antibodies, and P8 amines were bioconjugated to Alexa Fluor 555. This approach eliminates the need for the addition of HRP substrates and provided a $10^{4} \mathrm{pfu} / \mathrm{mL}$ LOD. However, the limited dynamic range resulted in saturation at $100 \mathrm{pfu} / \mathrm{strip}$. Setting aside the need for sophisticated optics, stability, and photobleaching of fluorogenic dyes, the approach illustrates dual conjugation to phage for sensitive detection of viruses.

Tests for circulating tumor cells (CTCs) promise to identify metastasizing cells for distinguishing cancer aggressiveness and monitoring the course of the disease. In particular, sensitivity, specificity, and cell viability for subsequent tumor heterogeneity analysis remain key unsolved challenges. Phage tends to adhere nonspecifically to cell surfaces and therefore could appear unlikely to solve these challenges. However, we have generated viruses modified with various architectures of PEG and PEGylated ligands for prostate cancer cell detection. ${ }^{61}$ The PEG derivatives were functionalized with azides or maleimides, and conjugated to phage noncovalently coated with oligolysine $\left(\mathrm{Lys}_{14}\right)$ peptide "wrappers" functionalized with alkyne or thiol, Figure 4. The oligolysine wrappers utilize the high negative charge present on the phage surface to electrostatically bind to the phage. PEG polymers provide an $\sim 80 \%$ reduction in nonspecific binding, and the ligands selectively capture PSMApositive LNCaP cells. ${ }^{61} \mathrm{We}$ plan to incorporate these PEGylated viruses in biosensors for the sensitive detection of cells. In another study utilizing PEGylated phage, anti-Her2 antibodies were conjugated to P8 amines using a 6-armPEG15K-NHS linker for placement of $\sim 150$ antibodies per phage particle. Phage were also linked to magnetic particles conjugated to anti-P3 antibody. The group achieved an unprecedented $>90 \%$ capture efficiency, with $80 \%$ purity and $>85 \%$ cell viability. ${ }^{62}$

Toward detection of analytes at low concentrations, SERS provides a very sensitive technique acquiring Raman scattering signals from surface-adsorbed molecules. The enhancement in signal is obtained through the immobilization of $\mathrm{Au}$ or $\mathrm{Ag}$ noble metal NPs on phage. ${ }^{43}$ Phage binding to the cells generated a distinct shift in Raman peaks, which benefits from Ag nanoparticles providing a much higher signal-to-noise ratio. In this assay, cells were immobilized for detection; ${ }^{63}$ thus, capture efficiency and sensitivity require further development.

In another interesting approach, Cha and co-workers used phosphine-stabilized Au NPs aggregated with thiolated-phage to provide an optical indicator of antigen binding to phage. Thiolated phage were generated by covalent conjugation to cysteamine or $\mathrm{N}$-succinimidyl 3-[2-pyridyldithio]-propionate (SPDP) allowing detection by Au NPs or DNA-modified $\mathrm{Au}$ NPs through DNA hybridization. ${ }^{64,65}$ Next, P8s on IgG-binding phage were modified with aldehyde groups through reaction with succinimidyl 4-formylbenzoate; the aldehyde conjugates hydrazine-derivatized DNA. In parallel, Au NPs were modified with DNA, Cy3, and Ag; the latter can generate a SERS signal. In these applications, phage provides an ideal benchtop for conjugation to multiple entities, which leads to an enhanced signal-to-noise ratio. ${ }^{66}$
Fluorophores such as Alexa Fluor, conjugated to P8 amines, have also been employed by Belcher and co-workers for bacterial cell detection and imaging. The P3 proteins were genetically modified to display BAP (Biotin Acceptor Peptide), which after biotinylation bound to a streptavidin-modified antibody for $S$. aureus. As expected, phage, due to its inherent binding for $\mathrm{F}^{+}$cells, detected such $E$. coli strains without the need for further modification with antibodies. The detection and imaging were also performed in vivo, ${ }^{67}$ though for efficient treatment with antibiotics, the specificity of bacterial strain detection would be crucial.

Phage As a Biological Recognition Unit in Biosensors. Phage can serve as a cost-effective, easily modifiable alternative to antibodies and also holds the potential for label-free detection. The approaches to phage incorporation in biosensors can be classified as either covalent or noncovalent.

For example, covalent incorporation of phage into chips allowed light addressable potentiometric sensing of the MDAMB-231 cancer cell line. The APTES-treated silicon nitride chip surfaces were cross-linked with P8 amines by glutaraldehyde. Like most such approaches, the chip surface required blocking with bovine serum albumin to prevent nonspecific signal generation. This design proved useful for the detection of bigger objects such as cells, but ineffective at detecting smaller biomolecules. $^{68}$

Similarly, we have developed bioelectronic sensors with phage covalently attached to Au surfaces modified with NHSthioctic ester. P8 amines reacted with the activated NHS esters immobilizing the phage. Electrochemical impedance spectroscopy provided a corresponding readout for analyte binding to phage as an increase in the impedance. ${ }^{69,70}$ A 120 nM LOD was obtained for prostate-specific membrane antigen (PSMA) through recognition by phage-displayed peptide ligands. Despite the ease of detection, low signal-to-noise and sensitivity of detection were key issues with this initial sensor architecture; blocking with BSA was also required to suppress binding. ${ }^{69}$ In a subsequent study, the bioconjugation approach was used to tether phage to a quartz crystal microbalance providing a $7 \mathrm{nM}$ LOD for the analyte. ${ }^{71}$

Noncovalent incorporation of phage into biosensors invariably relies on the surface charge of phage. The biggest advantage of using this method, besides the need for little or no other chemical reagents required, is the tunability of the resulting film. In general, the surface charge and thickness can be easily modified. Mao and co-workers modified the phage surface charge to generate a polycationic surface through display of four arginine residues. Next, LBL assembly was used to generate alternating films of such viruses and negatively charged Au nanoparticles, simply by interchangeably immersing in each solution. The resulting nanocomposite films displayed a unique SPR spectrum, which was responsive to environmental humidity due to its effect on inter-nanoparticle spacing. ${ }^{72}$

To improve the sensitivity of our device, we switched to noncovalent immobilization of phage in electrically conducting films. Composite films were deposited on the surface of a planar gold electrode consisting of a conducting organic polymer PEDOT (poly-3,4 ethylenedioxythiophene) into which virus particles are incorporated during polymerization. PEDOT in perchlorate solution undergoes an oxidation reaction resulting in a p-doped, positively charged polymer. These PEDOT units associate with the negatively charged phage as the counterion during deposition on gold. PEDOTnanowires synthesized via lithographic patterning provided a 66 
nM LOD in synthetic urine, ${ }^{73}$ whereas a film-based architecture provided a $6 \mathrm{nM}$ LOD for anti-M13 antibody. ${ }^{74,75}$ This detection approach is label-free (i.e., does not require the addition of a redox reporter) and also does not require surface passivation to prevent nonspecificity. The remaining challenge at this stage of the technology development was to improve the sensitivity required for cancer biomarker detection. ${ }^{74}$

In a subsequent study, we utilized the concept of noncovalent phage wrapping to maximize the density of ligands present on the surface of the phage for increased sensitivity through avidity effects and bidentate synergistic binding. One ligand to PSMA was genetically displayed through the phagemid system, and the second peptide ligand was conjugated to an oligolysine $\left(\mathrm{Lys}_{14}\right)$ peptide, which wraps around the phage surface due to electrostatic interactions, Figure 4. This strategy allowed detection of PSMA at $100 \mathrm{pM}$ concentrations in synthetic urine with an osmolality of 516.2 $\mathrm{mOsm} / \mathrm{kg}^{76,77}$ The technique is currently being developed into a point-of-care detection device.

Phage-based electrochemical immunosensors have also been applied toward the detection of small molecules such as the herbicide atrizine, which conventionally is detected through competitive assays with low sensitivity. In one report, a phagedisplaying peptide specifically recognizes the atrazine-capture antibody complex on magnetic beads. Then, HRP-conjugated anti-M13 antibody bound to the phage catalyzes the conversion of pyrocatechol to benzoquinone, which can be analyzed by chronoamperometry. ${ }^{78}$

In addition to the standard applications of phage-displayed peptides in biosensors, colorimetric sensors termed "phage litmus" have also been designed. Lee and co-workers demonstrate the use of self-templated assembly of trinitrotoluene-binding peptides displayed on phage, to generate bundles that undergo structural changes upon analyte binding providing a 300 ppb LOD. ${ }^{79}$ This example leverages the self-templated assembly of phage for a novel detection modality.

Phage As a Biological Template for Material Design. The precise assembly of nanoscale building blocks for the generation of complex structures in optical, electronic, magnetic devices or materials is often critical to their resultant functions. Toward this goal, hybrid organic and biological molecules allow assembly into specific structures. Phage, anisotropic, with relatively monodispersed size and shape, provides an easily functionalizable surface for such material generation. Furthermore, peptides displayed on phage with $20 \%$ incorporation rates will be $\sim 3 \mathrm{~nm}$ apart. ${ }^{80}$ Phage tend to self-organize with long-range order, such as liquid crystalline structures.

$1 \mathrm{D}$-micro and nanosized phage fibers with high surface-tovolume ratios can be generated through electrospinning with glutaraldehyde cross-linking. Belcher and co-workers showed the generation of virus-PVP (polyvinylpyrrolidone, a highly water-soluble material) composite fibers with nematic ordered morphologies. ${ }^{81}$ Phage-based functional fibers were achieved through conjugation of P8 carboxylates to amine-functionalized cadmium selenide quantum dots prior to electrospinning. ${ }^{82}$ Silverized phage fibers, and coatings on Kevlar fibers have also been developed through electrostatic interactions and crosslinking. ${ }^{48}$ The surface charge on phage can also be altered by reacting the P8 amines with glutaric anhydride, providing multiple carboxylic acid residues. This highly anionic surface adheres to polyaniline, in the presence of poly sulfonated styrene to generate highly conductive composite fibers. ${ }^{83}$
Hybridization of DNA strands in DNA-phage conjugates can dictate specific geometries and therefore properties of the resultant materials. The versatility of the phage surface can provide specific attachment sites at either termini for DNA attachment and subsequent temperature-dependent reversible hybridization. Sortase-mediated bioconjugation on P3 or P9, which are on opposite ends of the phage, introduced maleimide-functionalities for attachment to thiolated-DNA strands. The method allowed sequential linking of three different phage types in specific orders. ${ }^{84}$

Two dimensional assembly of viruses has also been achieved for NP nucleation and other purposes. Multilayers of oppositely charged polyelectrolytes, linear-polyethylenimine (LPEI), and poly(acrylic acid) (PAA) display characteristic interdiffusion between layers. A dropcast phage layer competes with PAA for binding to LPEI. The stronger affinity of PAA for LPEI forces the phage toward the surface and results in the formation of a highly ordered phage monolayer. ${ }^{85}$ These sandwiched stacks of LBL-assembled LPEI-PAA can be patterned using a capillaryassisted molding approach. ${ }^{86}$ Such LBL assemblies of phage have also been generated on carboxylate-functionalized graphene-oxide sheets. P3-displayed peptides with affinity for the carboxylate functionalities of graphene oxide can orient the phage, with further alignment provided by external shear force. Stacking of such layers generates ultrathin nanomesh membranes with highly selective pore sizes suitable for watertreatment applications. ${ }^{87}$

Inorganic Nucleation. In earlier studies, peptides binding to semiconductors with the selectivity to recognize crystal composition and crystalline faces were obtained through phage-displayed libraries. This work laid the foundation for organic materials to be used for the structural assembly of inorganic materials. ${ }^{88}$ Similarly, phage-displayed peptides were selected to recognize $\mathrm{ZnS}$ crystals and to direct alignment and nucleation into $3 \mathrm{D}$ smectic layered structures, ${ }^{89}$ quantum dot, highly conductive nanowires, ${ }^{90,91}$ and also superparamagnetic NPs. ${ }^{92}$

Multicomposite materials have also been generated through utilization of the polyanionic phage surface. Metals such as Rh, $\mathrm{Pd}$, and $\mathrm{Ru}$ complex to form cationic species in aqueous solutions. Such materials can nucleate on the phage surface. These aggregated NPs remain anchored on the surface after sodium borohydride reduction. For bifunctional materials, P3 proteins were genetically modified to bind $\mathrm{Fe}_{3} \mathrm{O}_{4}$ for magnetic separation. A key limitation of this approach is the failure to nucleate metals such as $\mathrm{Au}$ and $\mathrm{Pt}$, which typically form anionic species in solutions. ${ }^{93}$

The polyanionic phage surface has also been utilized to biomimic the composition and orientation of crystallized minerals for bone-like material fabrication. The biggest challenge in this area is the lack of precise control over $1 \mathrm{D}$ organization. Mao and co-workers loaded $\mathrm{Ca}^{2+}$ onto negatively charged phage to generate phage bundles held together by electrostatic interactions. Furthermore, the helically chiral phage surface allows precise alignment of $\mathrm{Ca}^{2+}$ for nucleation and crystallization of hydroxyapatite. ${ }^{94}$ Hierarchical fibril architecture resembling bone ECM was further achieved through the combination of collagen with $\mathrm{Glu}_{8}$ displaying phage for increased anionicity. ${ }^{95}$ The development of such biomaterials mimicking bone ECM could allow bone regeneration therapy especially in combination with bone repair as discussed above. In another example, phage films treated with an apatite precursor solution provided a template 
for biomineralization leading to the formation of tooth enamellike composites. ${ }^{96}$

Mesoporous Si structures have widely varied applications including catalysis, adsorbents, and drug delivery agents. However, the generation of highly ordered structures is a major challenge. In addition, the shape, size, and morphology of the pores can govern the incorporation of functional materials such as $\mathrm{Au}$ acting as a heterogeneous catalyst. The surface charge on phage can anchor APTES, which acts as nuclei for polycondensation of TEOS leading to templated $\mathrm{SiO}_{2}$ formation. ${ }^{97}$ Campero and co-workers applied phage reacted with $\mathrm{N}$-succinimidyl $\mathrm{S}$-acetylthioacetate or $\mathrm{N}$-succinimidyl $\mathrm{S}$ acetylthiopropionate to display thiols providing nucleation sites for metal NP formation. The Au NPs thus incorporated were catalytically active and allowed free flow of molecules due to encrustation in the silica walls after calcination. ${ }^{98}$ The phage, thus, can act as temporary spacers, which can be removed through high temperature treatment.

Catalytic nanowires composed entirely of noble metals increase the cost of preparation. As a result, noble metal nanowires have been synthesized with phage-based materials. Again, phage-displaying a peptide with affinity for $\mathrm{Au}$ provide powerful approaches to nanowire fabrication. The nanowires were extended to develop $\mathrm{Au}-\mathrm{Pt}$ core-shell nanowires. The composite noble metal system provided enhanced catalytic activity. ${ }^{99}$

Virus Batteries. Viruses have been used to design nanostructures for energy storage and conversion. A variety of materials and techniques have been employed for constructing exceptionally small batteries. Nanostructured materials hold the potential to improve secondary (rechargeable) batteries due to their monodispersed size and hierarchical organization. In an early study, dual-modified viruses allowed the generation of crystalline and uniformly packed $\mathrm{Co}_{3} \mathrm{O}_{4^{-}}$ phage nanowires, dispersed with $\mathrm{Au}$. Such an electrode provided greater reversible storage in comparison to the conventional graphite anode used in Li-ion batteries. ${ }^{100}$ Furthermore, placement of these virus-templated $\mathrm{Co}_{3} \mathrm{O}_{4}$ phage layers in the LBL assembly of solid-state polyelectrolyte LPEI-PAA system further improved electrochemical performance. $^{101}$

Enhanced electronic conductivity of active materials such as iron phosphate has indirectly been achieved through phage conjugation. Phage nucleating iron phosphate and conjugated to carbon SWNT serve as cathodes with no apparent effect on capacity retention in up to 50 cycles. ${ }^{102}$ Replacing $1 \mathrm{D}$-SWNT with $2 \mathrm{D}$-graphene in phage-based cathodes increases the battery's specific capacity. ${ }^{103}$ Additionally, SWNTs coated with polyaniline provide materials with high electrical conductivity. First, phage binding to SWNTs through a displayed peptide were cross-linked with glutaraldehyde to generate a hydrogel. A porous film of polyaniline was next synthesized on top of the hydrogel. The uniform and dense contact area between SWNTs and polyaniline results in high specific capacity. In addition, the phage eliminates the requirement for solubilizing agents for otherwise aggregationprone materials. ${ }^{104}$ In another variation, phage nucleating different compositions of transition metal (Co and $\mathrm{Mn}$ ) oxides provided over 2 -fold increased specific capacities. ${ }^{105}$

Methanol fuel cells offer multiple advantages, but the cost of noble metal electrodes deters their commercialization. Phage selectively modified to nucleate or conjugate $\mathrm{Au} / \mathrm{Ag} / \mathrm{Pt} \mathrm{NPs}$ can considerably reduce the cost with electroactivities in a range similar to conventional materials. First, the P8 amines were thiolated with NHS-acetylthiopropionate. The thiols allowed both selective conjugation of preformed NPs, and nucleation of metals from solution during NP formation. ${ }^{106}$

Phage, in addition to the characteristics detailed above, also exhibit piezoelectric properties due to the lack of an inversion center. The parallel coiled-coil P8 coat proteins have an inherent dipole from the $N$ - to $C$-termini, and the large net dipole inherent to phage allows generation of piezoelectricity. ${ }^{107}$ The energy-harvesting capabilities were further enhanced with the nanocrystal formation of perovskite-structured piezoelectric material, $\mathrm{BaTiO}_{3}$ on phage through charge-based nucleation of barium. ${ }^{108}$

Photosensitive Materials. The development of light harvesting systems requires efficient electron and energy transfer to the reaction center. The subnanometer-scale phage have been applied to allow precision nanoscale structuring to increase exciton flux, the transfer of energy without charge transfer. Furthermore, modification of the $\mathrm{N}$-terminal and Lys side chain amines on the P8 coat protein results in formation of FRET pairs with average distances of $<2.5 \mathrm{~nm}$. For artificial photosynthesis, these P8 amines were coupled through EDC activation of carboxylate-modified Zn-porphyrin complexes. This Zn-porphyrin phage showed an intense but broad Soret band at $406 \mathrm{~nm}$; the broadness could result from altered P8 structure due to Trp-porphyrin aromatic stacking interactions, which lead to different excited states. Furthermore, the exciton migration through FRET was verified through pump-probe transient absorption spectroscopy. ${ }^{109}$ This exciton migration ability of covalently modified phage was applied to the formation of a nanowire-based photoanode for dye-sensitized, anatase solar cells. This approach leveraged the abilities of phage films to nucleate mineral formation; deposition of $\mathrm{TiCl}_{4}$ preceded conversion to anatase. Similar to other examples, glutaraldehyde cross-linking provided a phage hydrogel. Hydrolysis at $80{ }^{\circ} \mathrm{C}$ and high temperature annealing at 450 ${ }^{\circ} \mathrm{C}$ convert the amorphous $\mathrm{TiCl}_{4}$ to form crystalline $\mathrm{TiO}_{2}$ (anatase), which improves electron collection. Additionally, phage can bind $\mathrm{Au}$ NPs prior to anatase coating for efficient optical absorption. ${ }^{110,111}$

The conjugation of azo compounds to biomolecules can impart reversible photoresponsivity. However, such modifications have largely not been extended to materials in higher dimensional architecture. Phage forming higher ordered selfassembled structures could potentially solve this challenge. Toward this goal, phage were genetically modified to display Tyr on P8, which were then converted to azo compounds by diazotization with p-substituted anilines. The resultant azophage complex retains the photoswitchable cis-trans isomerization of the azo functionality. ${ }^{112}$ This photoswitchable isomerization has also been used to develop light-responsive ligands using a disulfide-constrained library. The azo functionality was introduced through disulfide reduction followed by reaction with 3,3'-bis(sulfonato)-4, $4^{\prime}$-bis(chloroacetamido)azobenzene. $^{113}$

Phage-based photosensitizers have also been developed for photodynamic therapy. $\mathrm{N}$-terminal amines were conjugated to a photosensitizer. Peptides displayed on P8 provided affinity for the target cancer cells. Illumination with light at $658 \mathrm{~nm}$ generated cytotoxic singlet oxygen species. ${ }^{114}$

Chemical Modification for Selections. Chemical modifications of phage can also increase the scope of phage-displaybased selections. For example, glycopeptide ligands to lectins 
such as concavalin A have also been achieved using phage with both genetic and chemical modifications. Derda and co-workers conjugated a P3-displayed library with mannose. The $\mathrm{N}$ terminal Ser was first converted to aldehyde (Figure 2) and subsequently reacted with aminooxy-functionalized mannose. ${ }^{115,116}$ In another approach, a P3 displayed library containing a free Cys was conjugated to mannose through the formation of a disulfide bond through the use of 2-(3nitropyridyl disulfide ethyl)-mannopyranoside. ${ }^{117}$ Such methods present an alternative form of synergistic binding mode obtained through the use of phage. Furthermore, synergistic binding-based selections have also been performed with a phage-displayed Cys containing peptide library, conjugated to a predetermined maleimide-functionalized ligand. The approach provided a much higher affinity through an extended ligand system. ${ }^{118}$ Cyclic peptide libraries have also been generated on phage P3 proteins. First, a peptide library containing three reactive Cys is genetically displayed. Next, cyclization is achieved through reaction with tris(bromomethyl)benzene, providing two peptide loops (Figure 3). ${ }^{119}$

\section{CONCLUSIONS}

As illustrated here, phage provide an exceedingly flexible benchtop for the inclusion of a wide-range of useful functionalities. Such functionalities and multiple modalities on the phage surface can result from a combination of chemical and genetic modifications. Future examples will combine and extend such modifications in synergistic, novel ways. For example, we imagine applications with flotillas of modified viruses providing targeting, imaging, cell killing, gene delivery, and tissue regenerating functionalities for patient-specific diagnosis and treatment. To date, examples described here report cooperativity for up to two such functions, but multifunctional viruses could improve healthcare and materials in dramatic new ways. To accomplish such multifunctionality, the orthogonal reactions described above could be combined. For example, materials nucleation offers fascinating new properties for implantable sensors. Similarly, a combination of covalent and noncovalent modifications on the same phage particle could further broaden the scope of phage-based applications.

\section{AUTHOR INFORMATION}

\section{Corresponding Author}

*E-mail: gweiss@uci.edu.

\section{Notes}

The authors declare the following competing financial interest(s): For references 61, 69-71 and 73-77, this approach to biomarker sensing described by Dr. Weiss and co-workers has been licensed to PhageTech, a company co-founded by Dr. Weiss. PhageTech is developing products related to the research described in these references. The terms of this arrangement have been reviewed and approved by the University of California, Irvine in accordance with its conflict of interest policies.

\section{ACKNOWLEDGMENTS}

We gratefully acknowledge support from the National Institutes of Health through a grant from the NIGMS (1 RO1 GM100700-01). K.M. acknowledges support from the graduate fellowship awarded by the ACS division of Analytical Chemistry and sponsored by the Society for Analytical Chemists of
Pittsburgh (SACP), the Allergan graduate fellowship in synthetic organic chemistry, and the Taihi Hong memorial graduate student education award.

\section{ABBREVIATIONS}

Phage, M13 bacteriophage; EDC, 1-ethyl-3-(3(dimethylamino)propyl)carbodiimide; NHS, N-hydroxysuccinimide; NIR, near-IR wavelengths; SPARC, secreted protein, acidic and rich in cysteine; FITC, fluorescein isothiocyanate; FRET, fluorescence resonance energy transfer; SWNT, singlewalled carbon nanotube; PEG, polyethylene glycol; Dox, doxorubicin; NP, nanoparticle; ECM, extracellular matrix; LBL, layer-by-layer; LFA, lateral flow assay; LOD, limit of detection; SERS, surface enhanced Raman spectroscopy; PEDOT, poly-3,4 ethylenedioxythiophene; LPEI, linear-polyethylenimine; PAA, polyacrylic acid

\section{KEYWORDS}

Phage vector display: The display of a genetically encoded peptide on every copy of a phage coat protein; for example, display on every major coat protein, P8, is limited to peptides with six or fewer amino acids

Phagemid display: The display of peptides and proteins on coat proteins with a maximum of $10 \%$ incorporation; the remainder of the unmodified coat proteins are provided by a helper phage during propagation

Inherent phage functionalities: Easily accessible and modifiable side chain functionalities inherent to the phage coat proteins

Imparted phage functionalities: Functionalities such as aldehydes chemically installed onto the phage surface with or without the need for prior genetic modification

Phage wrapping: The concept of noncovalently covering the negatively charged phage surface with a positively charged peptide

Phage nucleation: The charge-based nucleation of cationic species, followed by reduction and oxidation to provide crystalline minerals

Biomimetic phage: The self-assembly of phage into liquid crystalline films with topographical features mimicking the extra-cellular matrix

PEGylated phage: Covalently or noncovalently coating the phage surface with the protein adhesion-resistant polymer, polyethylene glycol

\section{REFERENCES}

(1) Smith, G. P. (1985) Filamentous fusion phage: novel expression vectors that display cloned antigens on the virion surface. Science 228, 1315-1317.

(2) Russel, M., Lowman, H. B., and Tim, C. (2004) Phage Display: Practical Approach (Lowman, H. B., and Clackson, T., Eds.) Oxford University Press, New York.

(3) Sidhu, S. S., and Weiss, G. A. (2004) Phage Display: A Practical Approach (Lowman, H. B., and Clackson, T., Eds.) Oxford University Press, New York.

(4) Wan, J., Shu, H., Huang, S., Fiebor, B., Chen, I.-H., Petrenko, V. A., and Chin, B. A. (2007) Phage-Based Magnetoelastic Wireless Biosensors for Detecting Bacillus Anthracis Spores. IEEE Sens. J. 7, 470-477.

(5) Iannolo, G., Minenkova, O., Petruzzelli, R., and Cesareni, G. (1995) Modifying filamentous phage capsid: limits in the size of the major capsid protein. J. Mol. Biol. 248, 835-844. 
(6) Sidhu, S. S., Weiss, G. A., and Wells, J. A. (2000) High copy display of large proteins on phage for functional selections. J. Mol. Biol. 296, 487-495.

(7) Kehoe, J. W., and Kay, B. K. (2005) Filamentous phage display in the new millennium. Chem. Rev. 105, 4056-4072.

(8) Levin, A. M., and Weiss, G. A. (2006) Optimizing the affinity and specificity of proteins with molecular display. Mol. BioSyst. 2, 49-57.

(9) Jaworski, J. W., Raorane, D., Huh, J. H., Majumdar, A., and Lee, S.-W. (2008) Evolutionary screening of biomimetic coatings for selective detection of explosives. Langmuir 24, 4938-4943.

(10) Cho, W., Fowler, J. D., and Furst, E. M. (2012) Targeted binding of the M13 bacteriophage to thiamethoxam organic crystals. Langmuir 28, 6013-6020.

(11) Maeda, Y., Javid, N., Duncan, K., Birchall, L., Gibson, K. F., Cannon, D., Kanetsuki, Y., Knapp, C., Tuttle, T., Ulijn, R. V., and Matsui, H. (2014) Discovery of catalytic phages by biocatalytic selfassembly. J. Am. Chem. Soc. 136, 15893-15896.

(12) Mohan, K., and Weiss, G. A. (2014) Dual genetically encoded phage-displayed ligands. Anal. Biochem. 453, 1-3.

(13) Molek, P., and Bratkovič, T. (2015) Bacteriophages as Scaffolds for Bipartite Display: Designing Swiss Army Knives on a Nanoscale. Bioconjugate Chem. 26, 367-378.

(14) Li, K., Chen, Y., Li, S., Nguyen, H. G., Niu, Z., You, S., Mello, C. M., Lu, X., and Wang, Q. (2010) Chemical modification of M13 bacteriophage and its application in cancer cell imaging. Bioconjugate Chem. 21, 1369-1377.

(15) Jayanna, P. K., Bedi, D., Deinnocentes, P., Bird, R. C., and Petrenko, V. A. (2010) Landscape phage ligands for PC3 prostate carcinoma cells. Protein Eng., Des. Sel. 23, 423-30.

(16) Carrico, Z. M., Farkas, M. E., Zhou, Y., Hsiao, S. C., Marks, J. D., Chokhawala, H., Clark, D. S., and Francis, M. B. (2012) N-Terminal labeling of filamentous phage to create cancer marker imaging agents. ACS Nano 6, 6675-6680.

(17) Dwyer, M. A., Lu, W., Dwyer, J. J., and Kossiakoff, A. A. (2000) Biosynthetic phage display: a novel protein engineering tool combining chemical and genetic diversity. Chem. Biol. 7, 263-274.

(18) Sandman, K. E., Benner, J. S., and Noren, C. J. (2000) Phage Display of Selenopeptides. J. Am. Chem. Soc. 122, 960-961.

(19) Tian, F., Tsao, M.-L., and Schultz, P. G. (2004) A phage display system with unnatural amino acids. J. Am. Chem. Soc. 126, 1596215963.

(20) Liu, C. C., Mack, A. V., Tsao, M.-L., Mills, J. H., Lee, H. S., Choe, H., Farzan, M., Schultz, P. G., and Smider, V. V. (2008) Protein evolution with an expanded genetic code. Proc. Natl. Acad. Sci. U. S. A. 105, 17688-17693.

(21) Welsh, L. C., Symmons, M. F., Sturtevant, J. M., Marvin, D. A., and Perham, R. N. (1998) Structure of the capsid of Pf3 filamentous phage determined from X-ray fibre diffraction data at 3.1 A resolution. J. Mol. Biol. 283, 155-177.

(22) Hilderbrand, S. A., Kelly, K. A., Weissleder, R., and Tung, C.-H. (2005) Monofunctional near-infrared fluorochromes for imaging applications. Bioconjugate Chem. 16, 1275-1281.

(23) Kelly, K. A., Waterman, P., and Weissleder, R. (2006) In vivo imaging of molecularly targeted phage. Neoplasia 8, 1011-1018.

(24) Hilderbrand, S. A., Kelly, K. A., Niedre, M., and Weissleder, R. (2008) Near infrared fluorescence-based bacteriophage particles for ratiometric $\mathrm{pH}$ imaging. Bioconjugate Chem. 19, 1635-1639.

(25) Chen, L., Zhao, X., Lin, Y., Su, Z., and Wang, Q. (2014) Dual stimuli-responsive supramolecular hydrogel of bionanoparticles and hyaluronan. Polym. Chem. 5, 6754-6760.

(26) Chen, L., Wu, Y., Lin, Y., and Wang, Q. (2015) Virus-templated FRET platform for the rational design of ratiometric fluorescent nanosensors. Chem. Commun. 51, 10190-10193.

(27) Tian, Y., Wu, M., Liu, X., Liu, Z., Zhou, Q., Niu, Z., and Huang, Y. (2015) Probing the endocytic pathways of the filamentous bacteriophage in live cells using ratiometric $\mathrm{pH}$ fluorescent indicator. Adv. Healthcare Mater. 4, 413-419.

(28) Yi, H., Ghosh, D., Ham, M.-H., Qi, J., Barone, P. W., Strano, M. S., and Belcher, A. M. (2012) M13 phage-functionalized single-walled carbon nanotubes as nanoprobes for second near-infrared window fluorescence imaging of targeted tumors. Nano Lett. 12, 1176-1183.

(29) Ghosh, D., Bagley, A. F., Na, Y. J., Birrer, M. J., Bhatia, S. N., and Belcher, A. M. (2014) Deep, noninvasive imaging and surgical guidance of submillimeter tumors using targeted M13-stabilized singlewalled carbon nanotubes. Proc. Natl. Acad. Sci. U. S. A. 111, 1394813953.

(30) Hess, G. T., Cragnolini, J. J., Popp, M. W., Allen, M. A., Dougan, S. K., Spooner, E., Ploegh, H. L., Belcher, A. M., and Guimaraes, C. P. (2012) M13 bacteriophage display framework that allows sortasemediated modification of surface-accessible phage proteins. Bioconjugate Chem. 23, 1478-1487.

(31) Ghosh, D., Lee, Y., Thomas, S., Kohli, A. G., Yun, D. S., Belcher, A. M., and Kelly, K. A. (2012) M13-templated magnetic nanoparticles for targeted in vivo imaging of prostate cancer. Nat. Nanotechnol. 7, $677-682$.

(32) Wang, F., Liu, P., Sun, L., Li, C., Petrenko, V. A., and Liu, A. (2014) Bio-mimetic Nanostructure Self-assembled from Au@Ag Heterogeneous Nanorods and Phage Fusion Proteins for Targeted Tumor Optical Detection and Photothermal Therapy. Sci. Rep. 4, 6808.

(33) Rusckowski, M., Gupta, S., Liu, G., Dou, S., and Hnatowich, D. J. (2004) Investigations of a ${ }^{99 m} \mathrm{Tc}$-Labeled Bacteriophage as a Potential Infection-Specific Imaging Agent. J. Nucl. Med. 45, 12011208.

(34) Rusckowski, M., Gupta, S., Liu, G., Dou, S., and Hnatowich, D. $\mathrm{J}$. (2008) Investigation of four ${ }^{99 \mathrm{~m}} \mathrm{Tc}$-labeled bacteriophages for infection-specific imaging. Nucl. Med. Biol. 35, 433-440.

(35) Stevens, T. K., Palaniappan, K. K., Ramirez, R. M., Francis, M. B., Wemmer, D. E., and Pines, A. (2013) HyperCEST detection of a ${ }^{129}$ Xe-based contrast agent composed of cryptophane-A molecular cages on a bacteriophage scaffold. Magn. Reson. Med. 69, 1245-1252.

(36) Palaniappan, K. K., Ramirez, R. M., Bajaj, V. S., Wemmer, D. E., Pines, A., and Francis, M. B. (2013) Molecular imaging of cancer cells using a bacteriophage-based ${ }^{129} \mathrm{Xe}$ NMR biosensor. Angew. Chem., Int. Ed. 52, 4849-4853.

(37) Ng, S., Jafari, M. R., Matochko, W. L., and Derda, R. (2012) Quantitative synthesis of genetically encoded glycopeptide libraries displayed on M13 phage. ACS Chem. Biol. 7, 1482-1487.

(38) Kitov, P. I., Vinals, D. F., Ng, S., Tjhung, K. F., and Derda, R. (2014) Rapid, hydrolytically stable modification of aldehydeterminated proteins and phage libraries. J. Am. Chem. Soc. 136, $8149-8152$

(39) Vithayathil, R., Hooy, R. M., Cocco, M. J., and Weiss, G. A. (2011) The scope of phage display for membrane proteins. J. Mol. Biol. 414, 499-510.

(40) Bar, H., Yacoby, I., and Benhar, I. (2008) Killing cancer cells by targeted drug-carrying phage nanomedicines. BMC Biotechnol. 8, 37.

(41) Ghosh, D., Kohli, A. G., Moser, F., Endy, D., and Belcher, A. M. (2012) Refactored M13 bacteriophage as a platform for tumor cell imaging and drug delivery. ACS Synth. Biol. 1, 576-582.

(42) Suthiwangcharoen, N., Li, T., Li, K., Thompson, P., You, S., and Wang, Q. (2011) M13 bacteriophage-polymer nanoassemblies as drug delivery vehicles. Nano Res. 4, 483-493.

(43) Souza, G. R., Christianson, D. R., Staquicini, F. I., Ozawa, M. G., Snyder, E. Y., Sidman, R. L., Miller, J. H., Arap, W., and Pasqualini, R. (2006) Networks of gold nanoparticles and bacteriophage as biological sensors and cell-targeting agents. Proc. Natl. Acad. Sci. U. S. A. 103, $1215-1220$.

(44) Srinivasan, S., Alexander, J. F., Driessen, W. H., Leonard, F., Ye, H., Liu, X., Arap, W., Pasqualini, R., Ferrari, M., and Godin, B. (2013) Bacteriophage associated silicon particles: design and characterization of a novel theranostic vector with improved payload carrying potential. J. Mater. Chem. B 1, 5218-5229.

(45) Yacoby, I., Shamis, M., Bar, H., Shabat, D., and Benhar, I. (2006) Targeting antibacterial agents by using drug-carrying filamentous bacteriophages. Antimicrob. Agents Chemother. 50, 20872097. 
(46) Yacoby, I., Bar, H., and Benhar, I. (2007) Targeted drugcarrying bacteriophages as antibacterial nanomedicines. Antimicrob. Agents Chemother. 51, 2156-2163.

(47) Vaks, L., and Benhar, I. (2011) In vivo characteristics of targeted drug-carrying filamentous bacteriophage nanomedicines. J. Nanobiotechnol. 9, 58.

(48) Mao, J. Y., Belcher, A. M., and Van Vliet, K. J. (2010) Genetically Engineered Phage Fibers and Coatings for Antibacterial Applications. Adv. Funct. Mater. 20, 209-214.

(49) Rostovtsev, V. V., Green, L. G., Fokin, V. V., and Sharpless, K. B. (2002) A Stepwise Huisgen Cycloaddition Process: Copper(I)Catalyzed Regioselective Ligation of Azides and Terminal Alkynes. Angew. Chem., Int. Ed. 41, 2596-2599.

(50) Rong, J., Lee, L. A., Li, K., Harp, B., Mello, C. M., Niu, Z., and Wang, Q. (2008) Oriented cell growth on self-assembled bacteriophage M13 thin films. Chem. Commun., 5185-5187.

(51) Yoo, S. Y., Oh, J.-W., and Lee, S.-W. (2012) Phage-chips for novel optically readable tissue engineering assays. Langmuir 28, 21662172.

(52) Yoo, S. Y., Chung, W.-J., Kim, T. H., Le, M., and Lee, S.-W. (2011) Facile patterning of genetically engineered M13 bacteriophage for directional growth of human fibroblast cells. Soft Matter 7, 363368.

(53) Chung, W.-J., Merzlyak, A., and Lee, S.-W. (2010) Fabrication of engineered M13 bacteriophages into liquid crystalline films and fibers for directional growth and encapsulation of fibroblasts. Soft Matter 6, 4454.

(54) Wang, W., Chen, X., Li, T., Li, Y., Wang, R., He, D., Luo, W., Li, $\mathrm{X}$., and $\mathrm{Wu}, \mathrm{X}$. (2013) Screening a phage display library for a novel FGF8b-binding peptide with anti-tumor effect on prostate cancer. Exp. Cell Res. 319, 1156-1164.

(55) Wang, J., Wang, L., Yang, M., Zhu, Y., Tomsia, A., and Mao, C. (2014) Untangling the Effects of Peptide Sequences and Nanotopographies in a Biomimetic Niche for Directed Differentiation of iPSCs by Assemblies of Genetically Engineered Viral Nanofibers. Nano Lett. 14, 6850-6856.

(56) Wang, J., Yang, M., Zhu, Y., Wang, L., Tomsia, A. P., and Mao, C. (2014) Phage nanofibers induce vascularized osteogenesis in 3D printed bone scaffolds. Adv. Mater. 26, 4961-4966.

(57) Adhikari, M., Dhamane, S., Hagström, A. E. V, Garvey, G., Chen, W.-H., Kourentzi, K., Strych, U., and Willson, R. C. (2013) Functionalized viral nanoparticles as ultrasensitive reporters in lateralflow assays. Analyst 138, 5584-5587.

(58) Hagström, A. E. V, Garvey, G., Paterson, A. S., Dhamane, S., Adhikari, M., Estes, M. K., Strych, U., Kourentzi, K., Atmar, R. L., and Willson, R. C. (2015) Sensitive detection of norovirus using phage nanoparticle reporters in lateral-flow assay. PLoS One 10, e0126571.

(59) Adhikari, M., Strych, U., Kim, J., Goux, H., Dhamane, S., Poongavanam, M.-V., Hagström, A. E. V, Kourentzi, K., Conrad, J. C., and Willson, R. C. (2015) Aptamer-phage reporters for ultrasensitive lateral flow assays. Anal. Chem. 87, 11660-11665.

(60) Kim, J., Adhikari, M., Dhamane, S., Hagström, A. E. V, Kourentzi, K., Strych, U., Willson, R. C., and Conrad, J. C. (2015) Detection of viruses by counting single fluorescent genetically biotinylated reporter immunophage using a lateral flow assay. ACS Appl. Mater. Interfaces 7, 2891-2898.

(61) Mohan, K., and Weiss, G. A. (2015) Engineering chemically modified viruses for prostate cancer cell recognition. Mol. BioSyst. 11, 3264-3272.

(62) Jo, S.-M., Lee, J., Heu, W., and Kim, H.-S. (2015) Nanotentaclestructured magnetic particles for efficient capture of circulating tumor cells. Small 11, 1975-1982.

(63) Lentini, G., Fazio, E., Calabrese, F., De Plano, L. M., Puliafico, M., Franco, D., Nicolò, M. S., Carnazza, S., Trusso, S., Allegra, A., Neri, F., Musolino, C., and Guglielmino, S. P. P. (2015) Phage-AgNPs complex as SERS probe for U937 cell identification. Biosens. Bioelectron. 74, 398-405.
(64) Lee, J. H., and Cha, J. N. (2011) Amplified protein detection through visible plasmon shifts in gold nanocrystal solutions from bacteriophage platforms. Anal. Chem. 83, 3516-3519.

(65) Lee, J. H., Domaille, D. W., and Cha, J. N. (2012) Amplified protein detection and identification through DNA-conjugated M13 bacteriophage. ACS Nano 6, 5621-5626.

(66) Lee, J. H., Xu, P. F., Domaille, D. W., Choi, C., Jin, S., and Cha, J. N. (2014) M13 Bacteriophage as Materials for Amplified Surface Enhanced Raman Scattering Protein Sensing. Adv. Funct. Mater. 24, 2079-2084.

(67) Bardhan, N. M., Ghosh, D., and Belcher, A. M. (2014) M13 virus based detection of bacterial infections in living hosts. J. Biophotonics 7, 617-623.

(68) Jia, Y., Qin, M., Zhang, H., Niu, W., Li, X., Wang, L., Li, X., Bai, Y., Cao, Y., and Feng, X. (2007) Label-free biosensor: a novel phagemodified Light Addressable Potentiometric Sensor system for cancer cell monitoring. Biosens. Bioelectron. 22, 3261-3266.

(69) Yang, L.-M. C., Tam, P. Y., Murray, B. J., McIntire, T. M., Overstreet, C. M., Weiss, G. A., and Penner, R. M. (2006) Virus electrodes for universal biodetection. Anal. Chem. 78, 3265-3270.

(70) Yang, L.-M. C., Diaz, J. E., McIntire, T. M., Weiss, G. A., and Penner, R. M. (2008) Direct electrical transduction of antibody binding to a covalent virus layer using electrochemical impedance. Anal. Chem. 80, 5695-5705.

(71) Yang, L.-M. C., Diaz, J. E., McIntire, T. M., Weiss, G. A., and Penner, R. M. (2008) Covalent virus layer for mass-based biosensing. Anal. Chem. 80, 933-943.

(72) Liu, A., Abbineni, G., and Mao, C. (2009) Nanocomposite Films Assembled from Genetically Engineered Filamentous Viruses and Gold Nanoparticles: Nanoarchitecture- and Humidity-Tunable Surface Plasmon Resonance Spectra. Adv. Mater. 21, 1001-1005.

(73) Arter, J. A., Diaz, J. E., Donavan, K. C., Yuan, T., Penner, R. M., and Weiss, G. A. (2012) Virus-polymer hybrid nanowires tailored to detect prostate-specific membrane antigen. Anal. Chem. 84, 27762783.

(74) Donavan, K. C., Arter, J. A., Pilolli, R., Cioffi, N., Weiss, G. A., and Penner, R. M. (2011) Virus-poly(3,4-ethylenedioxythiophene) composite films for impedance-based biosensing. Anal. Chem. 83, $2420-2424$.

(75) Donavan, K. C., Arter, J. A., Weiss, G. A., and Penner, R. M. (2012) Virus-Poly(3,4-ethylenedioxythiophene) Biocomposite Films. Langmuir 28, 12581-12587.

(76) Mohan, K., Donavan, K. C., Arter, J. A., Penner, R. M., and Weiss, G. A. (2013) Sub-nanomolar Detection of Prostate-Specific Membrane Antigen in Synthetic Urine by Synergistic, Dual-Ligand Phage. J. Am. Chem. Soc. 135, 7761-7767.

(77) Mohan, K., Penner, R. M., and Weiss, G. A. (2015) Biosensing with Virus Electrode Hybrids. Curr. Protoc. Chem. Biol. 7, 53-72.

(78) González-Techera, A., Zon, M. A., Molina, P. G., Fernández, H., González-Sapienza, G., and Arévalo, F. J. (2015) Development of a highly sensitive noncompetitive electrochemical immunosensor for the detection of atrazine by phage anti-immunocomplex assay. Biosens. Bioelectron. 64, 650-656.

(79) Oh, J.-W., Chung, W.-J., Heo, K., Jin, H.-E., Lee, B. Y., Wang, E., Zueger, C., Wong, W., Meyer, J., Kim, C., Lee, S.-Y., Kim, W.-G., Zemla, M., Auer, M., Hexemer, A., and Lee, S.-W. (2014) Biomimetic virus-based colourimetric sensors. Nat. Commun. 5, 3043.

(80) Mao, C., Solis, D. J., Reiss, B. D., Kottmann, S. T., Sweeney, R. Y., Hayhurst, A., Georgiou, G., Iverson, B., and Belcher, A. M. (2004) Virus-based toolkit for the directed synthesis of magnetic and semiconducting nanowires. Science 303, 213-217.

(81) Lee, S.-W., and Belcher, A. M. (2004) Virus-Based Fabrication of Micro- and Nanofibers Using Electrospinning. Nano Lett. 4, 387390.

(82) Chiang, C.-Y., Mello, C. M., Gu, J., Silva, E. C. C. M., Van Vliet, K. J., and Belcher, A. M. (2007) Weaving Genetically Engineered Functionality into Mechanically Robust Virus Fibers. Adv. Mater. 19, 826-832. 
(83) Niu, Z., Bruckman, M. A., Harp, B., Mello, C. M., and Wang, Q. (2008) Bacteriophage M13 as a scaffold for preparing conductive polymeric composite fibers. Nano Res. 1, 235-241.

(84) Hess, G. T., Guimaraes, C. P., Spooner, E., Ploegh, H. L., and Belcher, A. M. (2013) Orthogonal labeling of M13 minor capsid proteins with DNA to self-assemble end-to-end multiphage structures. ACS Synth. Biol. 2, 490-496.

(85) Yoo, P. J., Nam, K. T., Qi, J., Lee, S.-K., Park, J., Belcher, A. M., and Hammond, P. T. (2006) Spontaneous assembly of viruses on multilayered polymer surfaces. Nat. Mater. 5, 234-240.

(86) Yoo, P. J., Nam, K. T., Belcher, A. M., and Hammond, P. T. (2008) Solvent-assisted patterning of polyelectrolyte multilayers and selective deposition of virus assemblies. Nano Lett. 8, 1081-1089.

(87) Lee, Y. M., Jung, B., Kim, Y. H., Park, A. R., Han, S., Choe, W.S., and Yoo, P. J. (2014) Nanomesh-structured ultrathin membranes harnessing the unidirectional alignment of viruses on a graphene-oxide film. Adv. Mater. 26, 3899-3904.

(88) Whaley, S. R., English, D. S., Hu, E. L., Barbara, P. F., and Belcher, A. M. (2000) Selection of peptides with semiconductor binding specificity for directed nanocrystal assembly. Nature 405, 665-668.

(89) Lee, S.-W. (2002) Ordering of Quantum Dots Using Genetically Engineered Viruses. Science 296, 892-895.

(90) Mao, C., Flynn, C. E., Hayhurst, A., Sweeney, R., Qi, J., Georgiou, G., Iverson, B., and Belcher, A. M. (2003) Viral assembly of oriented quantum dot nanowires. Proc. Natl. Acad. Sci. U. S. A. 100, 6946-69451.

(91) Huang, Y., Chiang, C.-Y., Lee, S. K., Gao, Y., Hu, E. L., Yoreo, J. D., and Belcher, A. M. (2005) Programmable Assembly of Nanoarchitectures Using Genetically Engineered Viruses. Nano Lett. 5, $1429-1434$

(92) Lee, S.-K., Yun, D. S., and Belcher, A. M. (2006) Cobalt ion mediated self-assembly of genetically engineered bacteriophage for biomimetic Co-Pt hybrid material. Biomacromolecules 7, 14-17.

(93) Avery, K. N., Schaak, J. E., and Schaak, R. E. (2009) M13 Bacteriophage as a Biological Scaffold for Magnetically-Recoverable Metal Nanowire Catalysts: Combining Specific and Nonspecific Interactions To Design Multifunctional Nanocomposites. Chem. Mater. 21, 2176-2178.

(94) Wang, F., Cao, B., and Mao, C. (2010) Bacteriophage Bundles with Pre-Aligned Ca Initiate the Oriented Nucleation and Growth of Hydroxylapatite. Chem. Mater. 22, 3630-3636.

(95) He, T., Abbineni, G., Cao, B., and Mao, C. (2010) Nanofibrous bio-inorganic hybrid structures formed through self-assembly and oriented mineralization of genetically engineered phage nanofibers. Small 6, 2230-2235.

(96) Chung, W.-J., Oh, J.-W., Kwak, K., Lee, B. Y., Meyer, J., Wang, E., Hexemer, A., and Lee, S.-W. (2011) Biomimetic self-templating supramolecular structures. Nature 478, 364-8.

(97) Mao, C., Wang, F., and Cao, B. (2012) Controlling nanostructures of mesoporous silica fibers by supramolecular assembly of genetically modifiable bacteriophages. Angew. Chem., Int. Ed. 51, 6411-6415.

(98) Vera-Robles, L. I., González-Gracida, J., Hernández-Gordillo, A., and Campero, A. (2015) Using the M13 Phage as a Biotemplate to Create Mesoporous Structures Decorated with Gold and Platinum Nanoparticles. Langmuir 31, 9188-9197.

(99) Lee, Y., Kim, J., Yun, D. S., Nam, Y. S., Shao-Horn, Y., and Belcher, A. M. (2012) Virus-templated $\mathrm{Au}$ and $\mathrm{Au}-\mathrm{Pt}$ core-shell nanowires and their electrocatalytic activities for fuel cell applications. Energy Environ. Sci. 5, 8328-8334.

(100) Nam, K. T., Kim, D.-W., Yoo, P. J., Chiang, C.-Y., Meethong, N., Hammond, P. T., Chiang, Y.-M., and Belcher, A. M. (2006) Virusenabled synthesis and assembly of nanowires for lithium ion battery electrodes. Science 312, 885-888.

(101) Nam, K. T., Wartena, R., Yoo, P. J., Liau, F. W., Lee, Y. J., Chiang, Y.-M., Hammond, P. T., and Belcher, A. M. (2008) Stamped microbattery electrodes based on self-assembled M13 viruses. Proc. Natl. Acad. Sci. U. S. A. 105, 17227-17231.
(102) Lee, Y. J., Yi, H., Kim, W.-J., Kang, K., Yun, D. S., Strano, M. S., Ceder, G., and Belcher, A. M. (2009) Fabricating genetically engineered high-power lithium-ion batteries using multiple virus genes. Science 324, 1051-1055.

(103) Oh, D., Dang, X., Yi, H., Allen, M. A., Xu, K., Lee, Y. J., and Belcher, A. M. (2012) Graphene sheets stabilized on genetically engineered M13 viral templates as conducting frameworks for hybrid energy-storage materials. Small 8, 1006-1011.

(104) Chen, P.-Y., Hyder, M. N., Mackanic, D., Courchesne, N.-M. D., Qi, J., Klug, M. T., Belcher, A. M., and Hammond, P. T. (2014) Hydrogels: Assembly of Viral Hydrogels for Three-Dimensional Conducting Nanocomposites. Adv. Mater. 26, 5069-5069.

(105) Oh, D., Qi, J., Han, B., Zhang, G., Carney, T. J., Ohmura, J., Zhang, Y., Shao-Horn, Y., and Belcher, A. M. (2014) M13 virusdirected synthesis of nanostructured metal oxides for lithium-oxygen batteries. Nano Lett. 14, 4837-4845.

(106) Vera-Robles, L. I., Van Tran Nhieu, G., Laberty-Robert, C., Livage, J., and Sanchez, C. (2013) Flexible Electroactive Nanomaterials Biotemplated with Versatile M13 Phage Platforms. Adv. Eng. Mater. 15, 954-961.

(107) Lee, B. Y., Zhang, J., Zueger, C., Chung, W.-J., Yoo, S. Y., Wang, E., Meyer, J., Ramesh, R., and Lee, S.-W. (2012) Virus-based piezoelectric energy generation. Nat. Nanotechnol. 7, 351-356.

(108) Jeong, C. K., Kim, I., Park, K.-I., Oh, M. H., Paik, H., Hwang, G.-T., No, K., Nam, Y. S., and Lee, K. J. (2013) Virus-Directed Design of a Flexible $\mathrm{BaTiO}_{3}$ Nanogenerator. ACS Nano 7, 11016-11025.

(109) Nam, Y. S., Shin, T., Park, H., Magyar, A. P., Choi, K., Fantner, G., Nelson, K. A., and Belcher, A. M. (2010) Virus-Templated Assembly of Porphyrins into Light-Harvesting Nanoantennae. J. Am. Chem. Soc. 132, 1462-1463.

(110) Chen, P.-Y., Dang, X., Klug, M. T., Qi, J., Dorval Courchesne, N.-M., Burpo, F. J., Fang, N., Hammond, P. T., and Belcher, A. M. (2013) Versatile three-dimensional virus-based template for dyesensitized solar cells with improved electron transport and light harvesting. ACS Nano 7, 6563-6574.

(111) Courchesne, N.-M. D., Klug, M. T., Chen, P.-Y., Kooi, S. E., Yun, D. S., Hong, N., Fang, N. X., Belcher, A. M., and Hammond, P. T. (2014) Assembly of a Bacteriophage-Based Template for the Organization of Materials into Nanoporous Networks. Adv. Mater. 26, 3398-3404.

(112) Murugesan, M., Abbineni, G., Nimmo, S. L., Cao, B., and Mao, C. (2013) Virus-based photo-responsive nanowires formed by linking site-directed mutagenesis and chemical reaction. Sci. Rep. 3, 1820.

(113) Jafari, M. R., Deng, L., Kitov, P. I., Ng, S., Matochko, W. L., Tjhung, K. F., Zeberoff, A., Elias, A., Klassen, J. S., and Derda, R. (2014) Discovery of light-responsive ligands through screening of a light-responsive genetically encoded library. ACS Chem. Biol. 9, 443450.

(114) Gandra, N., Abbineni, G., Qu, X., Huai, Y., Wang, L., and Mao, C. (2013) Bacteriophage Bionanowire as a Carrier for Both CancerTargeting Peptides and Photosensitizers and its use in Selective Cancer Cell Killing by Photodynamic Therapy. Small 9, 215-221.

(115) Ng, S., Lin, E., Kitov, P. I., Tjhung, K. F., Gerlits, O. O., Deng, L., Kasper, B., Sood, A., Paschal, B. M., Zhang, P., Ling, C.-C., Klassen, J. S., Noren, C. J., Mahal, L. K., Woods, R. J., Coates, L., and Derda, R. (2015) Genetically encoded fragment-based discovery of glycopeptide ligands for carbohydrate-binding proteins. J. Am. Chem. Soc. 137, $5248-5251$.

(116) Tjhung, K. F., Kitov, P. I., Ng, S., Kitova, E. N., Deng, L., Klassen, J. S., and Derda, R. (2015) Silent Encoding of Chemical PostTranslational Modifications in Phage-Displayed Libraries. J. Am. Chem. Soc. $138,32-35$.

(117) Arai, K., Tsutsumi, H., and Mihara, H. (2013) A monosaccharide-modified peptide phage library for screening of ligands to carbohydrate-binding proteins. Bioorg. Med. Chem. Lett. 23, 4940-4943.

(118) Santoso, B., Lam, S., Murray, B. W., and Chen, G. (2013) A simple and efficient maleimide-based approach for peptide extension 
with a cysteine-containing peptide phage library. Bioorg. Med. Chem.

Lett. 23, 5680-5683.

(119) Heinis, C., Rutherford, T., Freund, S., and Winter, G. (2009)

Phage-encoded combinatorial chemical libraries based on bicyclic peptides. Nat. Chem. Biol. 5, 502-507. 